\title{
Competitive Gold/Nickel Transmetalation
}

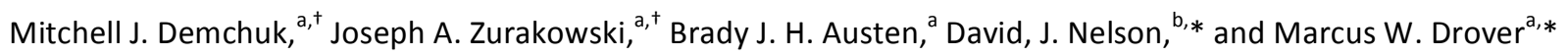

Transmetalation is a key method for the construction of element-element bonds. Here, we disclose the reactivity of [Ni"(Ar)(I)(diphosphine)] compounds with arylgold(I) transmetalating agents, which is directly relevant to crosscoupling catalysis. Both aryl-for-iodide and unexpected aryl-foraryl transmetalation are witnessed. Despite the strong driving force expected for Au-I bond formation, aryl scrambling can occur during transmetalation and may complicate the outcomes of attempted catalytic cross-coupling reactions.

The forging of metal-element bonds via transmetalation stands as a pivotal elementary step in catalytic cross-coupling for access to a variety of functionalized molecules, to the extent that crosscoupling reactions are defined and categorised by their transmetalation event. ${ }^{1}$ Frequently, this reaction follows substrate oxidative addition and precedes product reductive elimination. ${ }^{1}$ Many such coupling reactions have emerged, relying on electropositive metals for functional group ( $R$ ) delivery viz. Kumada $(R-M g B r)$, Suzuki $\left(R-B R_{2}\right)$, Negishi, $(R-Z n X)$, Stille $(R-$ $\left.\mathrm{SnR}_{3}\right)$, and Hiyama $\left(\mathrm{R}-\mathrm{SiR}_{3}\right)$, to name a few. ${ }^{1,2}$ As a germane study, in 2009, Hashmi et al. contributed to this growing list, introducing organogold(I) compounds ([R-Au( $\left.\left.L_{n}\right)\right] ; L_{n}=$ ligand) as competent partners for catalytic cross-coupling using palladium $(0)^{3}$

Blum and co-workers subsequently reported the room temperature $\left[\mathrm{NiCl}_{2}\left(\mathrm{PCy}_{3}\right)_{2}\right]$-catalysed cross-coupling of $[\mathrm{R}-$ $\left.\mathrm{Au}\left(\mathrm{PPh}_{3}\right)\right]$ complexes with aryl bromides. ${ }^{4}$ This reaction is proposed to proceed via an open-shell $\mathrm{Ni}$ complex wherein $\left[\mathrm{Ni}^{\prime \prime}(\mathrm{Cl})_{2}\left(\mathrm{PCY}_{3}\right)_{2}\right]$ first undergoes transmetalation with 2 equivalents of $\left[\mathrm{Ar}-\mathrm{Au}\left(\mathrm{PPh}_{3}\right)\right]$ to give $\left[\mathrm{Ni}(\mathrm{Ar})_{2}\left(\mathrm{PCY}_{3}\right)_{2}\right]$ and 2 equivalents of $\left[\mathrm{Cl}-\mathrm{Au}\left(\mathrm{PPh}_{3}\right)\right]$, presumably via $\left[\mathrm{Ni}^{\prime \prime}(\mathrm{Ar})(\mathrm{Cl})\left(\mathrm{PCy}_{3}\right)_{2}\right]$; subsequent halide transfer and oxidation by $\mathrm{Au}(\mathrm{I})$ gives $\left[\mathrm{Ni}^{\prime \prime \prime}(\mathrm{Ar})_{2}(\mathrm{Cl})(\mathrm{PCy})_{2}\right]$ and $\mathrm{Au}(0)$. This $\mathrm{Ni}^{\text {III }}$ species would thus reductively eliminate $\mathrm{Ar}-\mathrm{Ar}$ to provide $\left[\mathrm{Ni}^{\prime}(\mathrm{Cl})\left(\mathrm{PCy}_{3}\right)_{2}\right]$ and enter the catalytic cycle, undergoing transmetalation, oxidative addition, and reductive elimination, giving a $C-C$ coupled product. To buttress this proposal, the stoichiometric reaction of $\left[\mathrm{NiCl}_{2}\left(\mathrm{PCY}_{3}\right)_{2}\right]$ with 10 equivalents of $\left[\left(4-(\mathrm{MeO}) \mathrm{C}_{6} \mathrm{H}_{4}\right)-\mathrm{Au}\left(\mathrm{PPh}_{3}\right)\right]$ resulted in the homocoupled biaryl product, and a paramagnetic nickel complex that was characterised by EPR spectroscopy (Chart 1A). ${ }^{4}$

\footnotetext{
aepartment of Chemistry and Biochemistry, The University of Windsor, 401 Sunset Avenue, Windsor, ON, N9B 3P4, Canada.

marcus.drover@uwindsor.ca

b. WestCHEM Department of Pure and Applied Chemistry, University of Strathclyde, 295 Cathedral Street, Glasgow G1 1XL, Scotland

david.nelson@strath.ac.uk

+ These authors contributed equally.

${ }^{1} \mathrm{H},{ }^{13} \mathrm{C}\left\{{ }^{1} \mathrm{H}\right\},{ }^{31} \mathrm{P}\left\{{ }^{1} \mathrm{H}\right\}$, and ${ }^{11} \mathrm{~B}$ NMR spectra for all complexes. $\mathrm{XYZ}$ coordinates for DFT calculations. CCDC 2109283-2109284 contains the supplementary crystallographic data for this paper. These data can be obtained free of charge from The Cambridge Crystallographic Data Centre via www.ccdc.cam.ac.uk/data_request/cif. Computational chemistry data underpinning this study can be accessed via the ioChem-BD data repository at http://[TBA].
}

A. mechanistic proposal for $\mathrm{Au}$ activation of trans-[Ni(Cl)$\left.{ }_{2}\left(\mathrm{PCy}_{3}\right)_{2}\right](\mathrm{Blum}, 2011)$

$[\mathrm{Au}]=\mathrm{Au}\left(\mathrm{PPh}_{3}\right)$

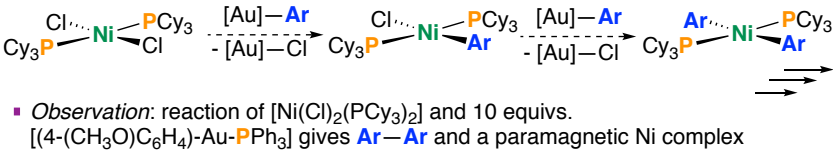

B. demonstrated role of Au in transmetalation (Blum, 2011 \& Hashmi, 2011)

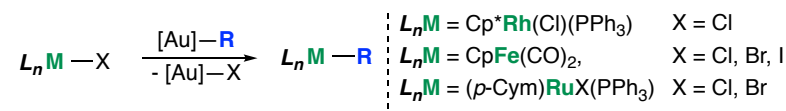

- reaction driven (in part) by formation of soft-soft $[\mathrm{Au}]-\mathrm{X}$ by-product

C. boranes are necessary for addition AND phosphine loss is irreversible

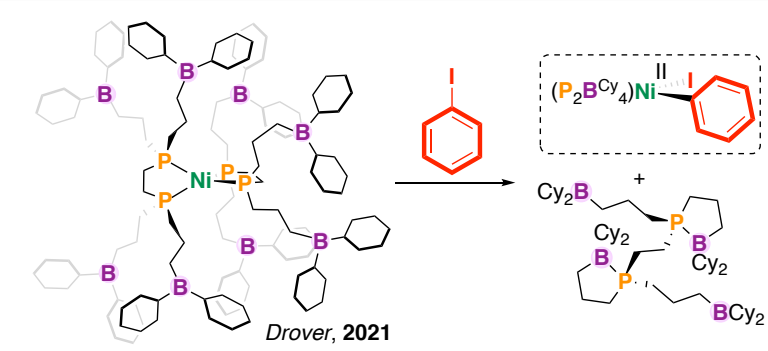

D. this work: aryl-for-aryl and aryl-for-iodide transmetalation

$$
\begin{aligned}
& \text { B } \\
& \text { B B } \\
& \text { B B }
\end{aligned}
$$

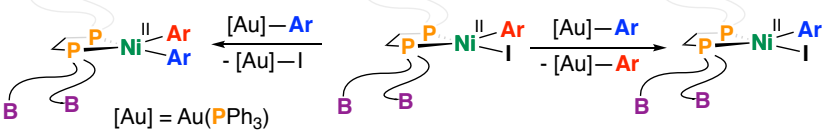

Chart 1. Literature precedent and accessing a [Ni(diphosphine $)(\operatorname{Ar})(X)]$ precursor and its reactivity with organogold(I) transmetalating reagents.

Organogold(I) compounds have proven to be competent for transmetalation to other transition metals such as $\left[\mathrm{CpFe}(\mathrm{CO})_{2}(\mathrm{X})\right]$ $\left(\mathrm{Cp}=\mathrm{C}_{5} \mathrm{H}_{5}^{-}, \mathrm{X}=\mathrm{Cl}, \mathrm{Br}, \mathrm{I}\right){ }^{5}\left[(p-\mathrm{Cym}) \mathrm{Ru}(\mathrm{X})_{2}\left(\mathrm{PPh}_{3}\right)\right](p$-Cym = p-cymene, $\mathrm{X}=\mathrm{Br}, \mathrm{I}){ }^{5}$ and $\left[\mathrm{Cp} * \mathrm{Rh}(\mathrm{Cl})_{2}\left(\mathrm{PPh}_{3}\right)\right]\left(\mathrm{Cp}^{*}=\mathrm{C}_{5} \mathrm{Me}_{5}{ }^{-}\right)\left(\right.$Chart 1B). ${ }^{6}$ For the reaction of $\left[\mathrm{CpFe}(\mathrm{CO})_{2}(\mathrm{X})\right]$ with $\left[\left(4-\left(\mathrm{NO}_{2}\right) \mathrm{C}_{6} \mathrm{H}_{4}\right)-\mathrm{Au}\left(\mathrm{PPh}_{3}\right)\right]$, the rate of reaction followed the order $\mathrm{I}>\mathrm{Br}>\mathrm{Cl}$, consistent with the high affinity of gold(I) for soft halides in the $\left[\mathrm{X}-\mathrm{Au}\left(\mathrm{PPh}_{3}\right)\right]$ by-product. ${ }^{5}$ We refer the interested reader to several reviews pertaining to [Au]- based transmetalations. ${ }^{7}$

As an entry-point into this research area, we recently reported the fundamental reactivity of a bis(diphosphine) $\mathrm{Ni}(0)$ complex, $\left[\mathrm{Ni}^{\mathrm{O}}\left(\mathrm{P}_{2} \mathrm{~B}^{\mathrm{Cy}}{ }_{4}\right)_{2}\right]\left(\mathrm{P}_{2} \mathrm{~B}^{\mathrm{Cy}}{ }_{4}=1,2-\right.$-bis (di(3-dicyclohexylboraneyl)propylphosphino)ethane) that undergoes room temperature iodoarene activation to afford $\left[\mathrm{Ni}^{11}\left(\mathrm{P}_{2} \mathrm{~B}^{\mathrm{CY}}{ }_{4}\right)(\mathrm{Ar})(\mathrm{I})\right]$ and $\mathrm{P}_{2} \mathrm{~B}^{\mathrm{Cy}}{ }_{4}$ (Chart 1C). ${ }^{8}$ This reaction is noteworthy as, generally-speaking, treatment of alkyl/aryl-substituted diphosphine complexes of the form $\left.\left[\mathrm{Ni}^{0} \text { (diphosphine) }\right)_{2}\right]$ with haloarenes does not result in $\mathrm{C}-\mathrm{X}$ bond activation, owing to the significant endergonicity associated with formation of the requisite $\left[\mathrm{Ni}^{0}\left(\kappa^{1}\right.\right.$-diphosphine $)\left(\kappa^{2}\right.$-diphosphine $\left.)\right]$ complex required for substrate activation; ${ }^{9}\left[\mathrm{Ni}^{0}(\mathrm{~d} n \mathrm{ppe}){ }_{2}\right](\mathrm{d} n \mathrm{ppe}=$ 
1,2-bis(di- $n$-propylphosphino)ethane) does not undergo oxidative addition under similar conditions.

To extend the reactivity of such $\mathrm{P}_{2} \mathrm{~B}^{\mathrm{Cy}}{ }_{4}$-ligated complexes, we elected to study the behaviour of $\left[\mathrm{Ni}^{\prime \prime}\left(\mathrm{P}_{2} \mathrm{~B}^{\mathrm{Cy}}{ }_{4}\right)(\mathrm{Ar})(\mathrm{I})\right]$ with a transmetalating reagent, as a means to explore the second elementary step in a viable cross-coupling sequence using $\left[\mathrm{Ni}^{0}\left(\mathrm{P}_{2} \mathrm{~B}_{4}{ }_{4}\right)_{2}\right]$. Our interests turned to $[\mathrm{Au}]$-based reagents owing to several alluring characteristics: these reagents are accurately weighed in small quantities, soluble in hydrocarbon solvent, readily tailored, and are unlikely to undergo transfer to the $s p^{2}$-hybridized boranes present on the $\mathrm{P}_{2} \mathrm{~B}^{\mathrm{Cy}}{ }_{4}$ ligand scaffold. ${ }^{8}$ Furthermore, these agents are bench-stable and provide $\left[\mathrm{X}-\mathrm{Au}\left(\mathrm{PPh}_{3}\right)\right]$ as a by-product, whose formation can be conveniently monitored by ${ }^{31} \mathrm{P}$ NMR spectroscopy. ${ }^{10}$ In addition to probing the stepwise reactivity of "[ $\left[\mathrm{Ni}^{0 / 11}\left(\mathrm{P}_{2} \mathrm{~B}^{\mathrm{CY}}\right){ }_{4}\right)$ "-type compounds, we were equally interested in contributing to the growing area of gold-to-metal transmetalations starting from a bona-fide [ $\mathrm{Ni}^{\text {"l }}$ (diphosphine)( $\left.\left.\mathrm{Ar}\right)(\mathrm{X})\right]$ complex, informing studies such as that noted for $\left[\mathrm{Ni}^{\prime \prime}\left(\mathrm{Cl}_{2}\left(\mathrm{PCy}_{3}\right)_{2}\right]\right.$, above. ${ }^{4}$

$\left[\mathrm{Ni}^{\prime \prime}\left(\mathrm{P}_{2} \mathrm{~B}^{\mathrm{Cy}}{ }_{4}\right)\left(4-\mathrm{FC}_{6} \mathrm{H}_{4}\right)(\mathrm{I})\right](2-\mathrm{F})$, generated from oxidative addition of 4-fluoroiodobenzene at $\left[\mathrm{Ni}\left(\mathrm{P}_{2} \mathrm{~B}^{\mathrm{Cy}}{ }_{2}\right)_{2}\right](\mathbf{1})$, was selected as the transmetalation partner, enabling reaction monitoring by ${ }^{19} \mathrm{~F} N \mathrm{NMR}$ spectroscopy. ${ }^{8}$ Transmetalation was examined using a number of gold(I) aryl compounds with an electron-donating or -withdrawing group at the para-position, $\left[\left(4-\mathrm{X}_{-} \mathrm{C}_{6} \mathrm{H}_{4}\right)-\mathrm{Au}\left(\mathrm{PPh}_{3}\right)\right]\left(\mathrm{X}=\mathrm{H}, \mathrm{OCH}_{3}\right.$, $\mathrm{CF}_{3}$ ) (Scheme 1). As a starting point, compound 2-F was combined with 1 equivalent of $\left[\left(\mathrm{C}_{6} \mathrm{H}_{5}\right)-\mathrm{Au}\left(\mathrm{PPh}_{3}\right)\right]$, and the reaction was analysed by NMR spectroscopy. Given the literature precedent noted above, we hypothesized that this would represent an ideal pairing, owing to favourable generation of $\left[1-\mathrm{Au}\left(\mathrm{PPh}_{3}\right)\right]$. However, monitoring the reaction by ${ }^{31} \mathrm{P}$ NMR spectroscopy evidenced formation of $\left[\mathrm{Ni}\left(\mathrm{P}_{2} \mathrm{~B}^{\mathrm{Cy}}{ }_{4}\right)\left(\mathrm{C}_{6} \mathrm{H}_{5}\right)(\mathrm{I})\right]^{8}(2-\mathrm{H})$ in $25 \%$ yield after 7 mins, resulting from 'aryl-to-aryl' transmetalation. The fate of the

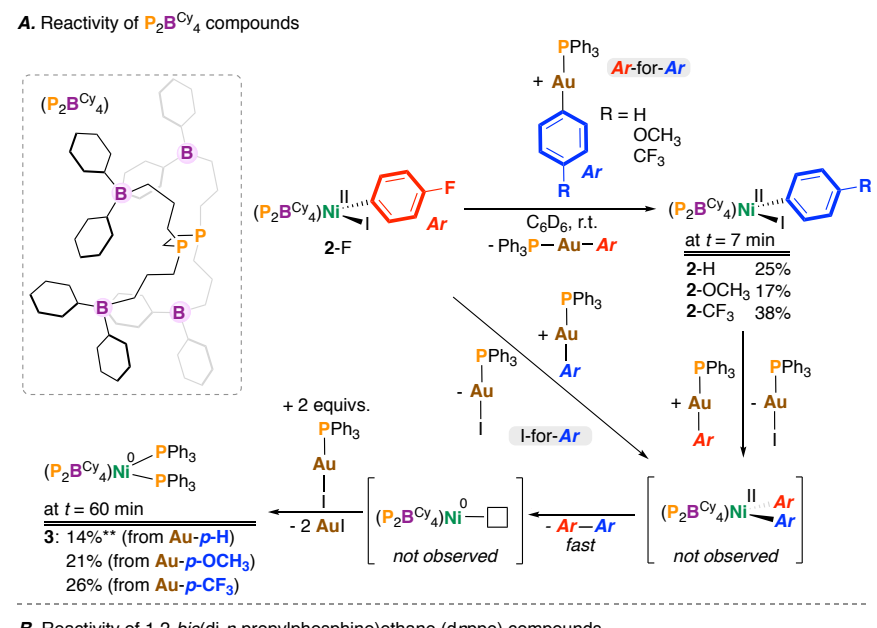

B. Reactivity of 1,2-bis(di-n-propylphosphino)ethane (dnppe) compounds

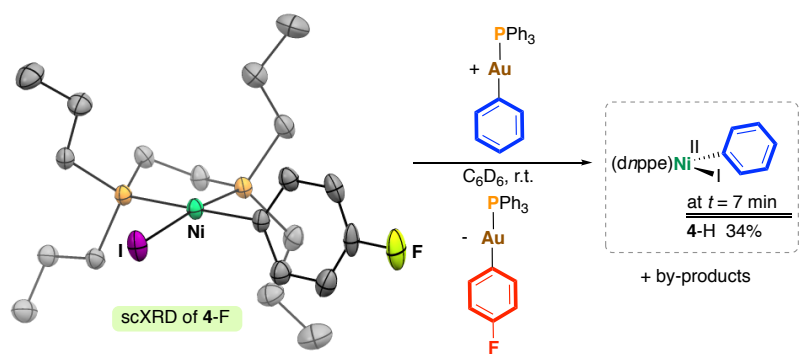

Scheme 1. Transmetalation of 2-F and 4-F using $\left[\mathrm{Ar}-\mathrm{Au}\left(\mathrm{PPh}_{3}\right)\right]$ reagents. Yields taken after $7 \mathrm{~min}$. Inset of $\mathbf{B}$ shows the scXRD structure of 4-F (50\% occupancy, hydrogens omitted for clarity). ${ }^{* *}$ The maximum theoretical yield of 3 is $50 \%$. dnppe $=1,2-b i s(d i-n$-propylphosphino)ethane. exchanged " $4-\mathrm{FC}_{6} \mathrm{H}_{4}$ " unit was deduced by ${ }^{19} \mathrm{~F}$ NMR spectroscopy, matching data reported for $\left[\left(4-\mathrm{FC}_{6} \mathrm{H}_{4}\right)-\mathrm{Au}\left(\mathrm{PPh}_{3}\right)\right] .{ }^{10}$ In addition to signals for $2-\mathrm{H}$, a signal at $\delta_{\mathrm{P}}=43 \mathrm{ppm}$ was also noted for [(4$\left.\left.\mathrm{FC}_{6} \mathrm{H}_{4}\right)-\mathrm{Au}\left(\mathrm{PPh}_{3}\right)\right]$ in the ${ }^{31} \mathrm{P}$ NMR spectrum. The formation of $4-$ fluorobiphenyl, from reductive elimination via $\left[\mathrm{Ni}\left(\mathrm{P}_{2} \mathrm{~B}_{4}{ }_{4}\right)(4-\right.$ $\left.\mathrm{FC}_{6} \mathrm{H}_{4}\right)\left(\mathrm{C}_{6} \mathrm{H}_{5}\right)$ ], was observed by ${ }^{19} \mathrm{~F}$ NMR spectroscopy, indicating that both Ar-for-Ar and Ar-for-I transmetalation processes are operative. The treatment of 2-F with 1 equivalent of $\left[\left(4-\mathrm{X}_{-} \mathrm{C}_{6} \mathrm{H}_{4}\right)-\right.$ $\left.\mathrm{Au}\left(\mathrm{PPh}_{3}\right)\right]\left(\mathrm{X}=\mathrm{OCH}_{3}, \mathrm{CF}_{3}\right)$ proceeded similarly to give $\left[\mathrm{Ni}\left(\mathrm{P}_{2} \mathrm{~B}^{\mathrm{Cy}}{ }_{4}\right)(4-\mathrm{X}\right.$ $\left.\left.\mathrm{C}_{6} \mathrm{H}_{4}\right)(I)\right]\left(2-\mathrm{X} ; \mathrm{X}=\mathrm{OCH}_{3}(17 \%), \mathrm{CF}_{3}(38 \%)\right)$ after 7 minutes of reaction time.

Compounds 2-X were found to be highly reactive under the conditions studied. The ultimate fate of [at maximum $50 \%$ ] Ni (after ca. 60 mins) in these elementary reactions is accounted for in the formation of $\left[\mathrm{Ni}^{0}\left(\mathrm{P}_{2} \mathrm{~B}^{\mathrm{CV}}{ }_{4}\right)\left(\mathrm{PPh}_{3}\right)_{2}\right](3) \delta_{\mathrm{P}}=34.8\left(\mathrm{t},{ }^{2} J_{\mathrm{P}, \mathrm{P}}=27 \mathrm{~Hz} ; \mathrm{PPh}_{3}\right)$, $19.7\left(t,{ }^{2} J_{P, P}=27 \mathrm{~Hz} ; \mathrm{P}_{2} \mathrm{~B}^{\mathrm{CV}}{ }_{4}\right)$, which forms via $\mathrm{PPh}_{3}$ transfer from $\mathrm{Au}$ following $C(A r)-C(A r)$ reductive elimination in yields ranging from $14-26 \%$, based on $\mathrm{Ni}$ (Scheme 1). The observation of some $S=0$ $\mathrm{Ni}(0)$ product is suggestive of a $\mathrm{Ni}(0) / \mathrm{Ni}(\mathrm{II})$ elimination pathway. The identity of compound $\mathbf{3}$ was confirmed by its independent preparation from the reaction of $\left[\mathrm{Ni}^{0}\left(\mathrm{P}_{2} \mathrm{~B}^{\mathrm{Cy}}{ }_{4}\right)_{2}\right]$ with 2 equivalents of $\mathrm{PPh}_{3}$. This reaction illustrates the lability of the $\mathrm{P}_{2} \mathrm{~B}^{\mathrm{Cy}}{ }_{4}$ ligand scaffold; the related species $\left[\mathrm{Ni}^{0}(\mathrm{~d} n \mathrm{ppe})_{2}\right]$, which is devoid of pendant boranes, does not undergo ring-opening and $\mathrm{PPh}_{3}$ coordination.

To demonstrate the generality of our observations regarding transmetalation between gold and nickel, and to show that this is not a boron effect, $\left[\mathrm{Ni}(\mathrm{d} n \mathrm{ppe})\left(4-\mathrm{FC}_{6} \mathrm{H}_{4}\right)(\mathrm{I})\right] \quad(4-\mathrm{F})$ (see $\mathrm{SI}$ ) was prepared, characterized, and exposed to 1 equiv. of $\left[\left(\mathrm{C}_{6} \mathrm{H}_{5}\right)-\right.$ $\left.\mathrm{Au}\left(\mathrm{PPh}_{3}\right)\right]$. Analysis of the reaction mixture after $7 \mathrm{~min}$ by NMR spectroscopy showed formation of [ $\left.\mathrm{Ni}(\mathrm{d} n \mathrm{ppe})\left(\mathrm{C}_{6} \mathrm{H}_{5}\right)(\mathrm{I})\right](4-\mathrm{H})$ in $34 \%$ yield, consistent with previous results for $\mathrm{P}_{2} \mathrm{~B}^{\mathrm{Cy}}$.

The relevance of such compounds viz. $\left[\mathrm{Ni}\left(\mathrm{P}_{2} \mathrm{~B}^{\mathrm{Cy}}{ }_{4}\right)_{2}\right](\mathbf{1})$ in crosscoupling was also confirmed with $10 \mathrm{~mol} \% 1$ enabling the crosscoupling of 4-fluoroiodobenzene and $\left[\left(4-\mathrm{FC}_{6} \mathrm{H}_{4}\right)-\mathrm{Au}\left(\mathrm{PPh}_{3}\right)\right]$, delivering the corresponding biaryl in $86 \%$ conversion by ${ }^{19} \mathrm{~F} \mathrm{NMR}$ spectroscopy.

To probe the thermodynamics associated with transmetalation, density functional theory (DFT) $)^{11}$ and DLPNO-CCSD(T) calculations ${ }^{12}$ were carried out on a model reaction between [ $\mathrm{Ni}^{\mathrm{i}}(\mathrm{d} n \mathrm{ppe})(4-$ $\left.\left.\mathrm{FC}_{6} \mathrm{H}_{4}\right)(\mathrm{I})\right]$ and $\left[\left(\mathrm{C}_{6} \mathrm{H}_{5}\right)-\mathrm{Au}\left(\mathrm{PPh}_{3}\right)\right]$ (Scheme 2). In all cases, there was excellent agreement between DFT and high-level DLPNO-CCSD(T) calculations. The data from DLPNO-CCSD $(T)$ calculations is discussed in the text, but DFT-derived energies are reported in Scheme $\mathbf{2}$ and in the ESI. The transmetalation reaction between $\left[\mathrm{Ni}(\mathrm{I})_{2}(\mathrm{~d} n \mathrm{ppe})\right]$ and $\left[\left(\mathrm{C}_{6} \mathrm{H}_{5}\right)-\mathrm{Au}\left(\mathrm{PPh}_{3}\right)\right]$ is thermodynamically favourable, with $\Delta \mathrm{G}^{\circ}=$ $-4.3 \mathrm{kcal} \mathrm{mol}^{-1}$. However, the outcomes from I-for-Aryl and Ar-for-Ar transmetalation at 4-F were less favourable. Somewhat surprisingly, the exchange of iodine for phenyl is endergonic $\left(\Delta \mathrm{G}^{\circ}=1.0 \mathrm{kcal} \mathrm{mol}^{-}\right.$ ${ }^{1}$ ). The exchange of para-fluorophenyl for phenyl (i.e. formation of 4-H from 4-F) is energetically neutral $\left(\Delta \mathrm{G}^{\circ}=-0.1 \mathrm{kcal} \mathrm{mol}^{-1}\right)$. In the context of catalysis, the product of I-for-Ar transmetalation can undergo reductive elimination, thereby driving catalysis forward if the overall reaction is exergonic; however, these experimental and computational results indicate the potential for aryl scrambling during cross-coupling reactions, eroding reaction selectivity and forming undesired homocoupling products.

Previously, we showed that $\left[\mathrm{Ni}\left(\mathrm{P}_{2} \mathrm{~B}^{\mathrm{Cy}}{ }_{4}\right)_{2}\right](\mathbf{1})$ coordinates Lewis bases, binding up to eight equivalents of $4-\mathrm{N}, \mathrm{N}-$ dimethylaminopyridine (DMAP). ${ }^{13}$ We wondered whether an appropriate gold(I)-pyridyl fragment (i.e. [Au]- $\left(4-\mathrm{NC}_{5} \mathrm{H}_{4}\right)$ ) might instead be used for coordination. In this regard, the $\mathrm{P}_{2} \mathrm{~B}^{\mathrm{Cy}}{ }_{4}$ ligand 


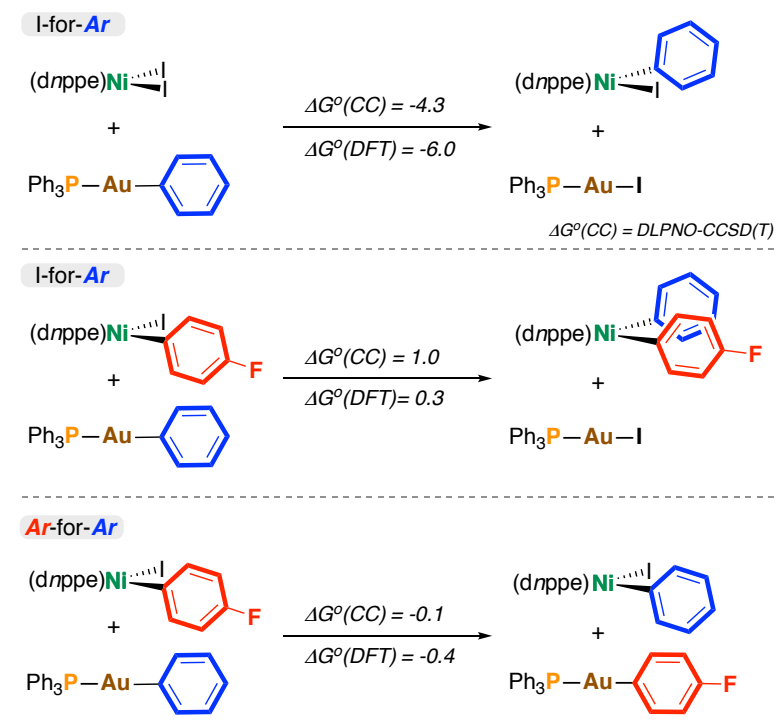

Scheme 2. Thermodynamics of transmetalation ( $\left.\mathrm{kcal} \mathrm{mol}^{-1}\right) \cdot \Delta G^{\circ}(\mathrm{CC})$ was calculated using DLPNO-CCSD(T), $\Delta G^{\circ}(\mathrm{DFT})$ was calculated using DFT. $^{11,12}$

would serve in a directing capacity, luring transmetalating agents into close proximity with a $\mathrm{Ni}(\mathrm{II})$ fragment that can undergo transmetalation. With this proposal in mind, the new compound, $\left[\left(4-\mathrm{NC}_{5} \mathrm{H}_{4}\right)-\mathrm{Au}\left(\mathrm{PPh}_{3}\right)\right](5)$ was prepared via the reaction of $[\mathrm{Br}-$ $\left.\mathrm{Au}\left(\mathrm{PPh}_{3}\right)\right]$ with 4-pyridylboronic acid and was isolated as a white crystalline solid in $75 \%$ yield (Scheme $3 \mathbf{A}){ }^{14}$ Formation of $\mathbf{5}$ is substantiated by NMR spectroscopy ( $\delta_{\mathrm{p}}=43 \mathrm{ppm}$ ) and single crystal $X$-ray diffraction, which evidences formation of a linear gold(I) unit $\left(<\mathrm{P}-\mathrm{Au}-\mathrm{C}=180^{\circ}\right)$ (Scheme 3A). Importantly, compound 5 boasts an accessible Lewis basic pyridine, allowing for possible interaction with the pendant boraneyl groups of $\left[\mathrm{Ni}\left(\mathrm{P}_{2} \mathrm{~B}^{\mathrm{Cy}}{ }_{4}\right)_{2}\right](\mathbf{1})$.

The reaction of $\mathbf{1}$ with 8 equivalents of $\mathbf{5}$ in $\mathrm{THF}^{15}$ provided an immediate colour change from light yellow to dark brown to give $\left[\mathrm{Ni}^{0}\left(\mathrm{P}_{2} \mathrm{~B}^{\mathrm{Cy}}{ }_{4}\right)_{2}\left\{\left(4-\mathrm{NC}_{5} \mathrm{H}_{4}\right)-\mathrm{Au}^{\prime}\left(\mathrm{PPh}_{3}\right)\right\}_{8}\right]$ (6) (Scheme 3B). Analysis by ${ }^{31} \mathrm{P}$ NMR spectroscopy (THF- $\mathrm{d}_{8}$ ) provided two broad signals at $\delta_{\mathrm{P}}=$ 42 and $36 \mathrm{ppm}$ that are shifted upfield compared to uncoordinated $\mathbf{5}\left(\Delta \delta_{p}=-1 \mathrm{ppm}\right)$ and $\mathbf{1}\left(\Delta \delta_{\mathrm{p}}=-3 \mathrm{ppm}\right)$ (see ESI). ${ }^{13}$ Consistent with an array of interacting borane-pyridine groups, the ${ }^{31} \mathrm{P}$ NMR signature for the equivalent $[\mathrm{Ni}]-\mathrm{P}$ fragments is similar to $\left[\mathrm{Ni}^{0}\left(\mathrm{P}_{2} \mathrm{~B}_{4}{ }_{4}\right)_{2}(\mathrm{DMAP})_{8}\right]\left(\delta_{\mathrm{P}}=35 \mathrm{ppm}\right) .{ }^{13}$ No signal is detected by ${ }^{11} \mathrm{~B}$ NMR spectroscopy at $298 \mathrm{~K} \mathrm{cf}$. $\delta_{\mathrm{B}}=84 \mathrm{ppm}$ for free $\left[\mathrm{Ni}^{0}\left(\mathrm{P}_{2} \mathrm{~B}^{\mathrm{Cy}}{ }_{4}\right)_{2}\right]$ and $\delta_{\mathrm{B}}=+4 \mathrm{ppm}$ for $\left[\mathrm{Ni}^{0}\left(\mathrm{P}_{2} \mathrm{~B}^{\mathrm{Cy}}{ }_{4}\right)_{2}(\mathrm{DMAP})_{8}\right] .{ }^{13}$ To probe the possibility of fluxional solution behaviour, a variable temperature (VT) NMR study was undertaken. On decreasing the temperature to $193 \mathrm{~K}$, the ${ }^{31}$ P NMR spectrum changes markedly; the broad signal associated with $[\mathrm{Au}]-P$ groups decoalesces, while the signal for the $[\mathrm{Ni}]-P$ groups moves upfield and the baseline broadens (see ESI). Fluxional behaviour is also witnessed by VT ${ }^{11} \mathrm{~B}$ NMR spectroscopy, which at $263 \mathrm{~K}$ shows an averaged signal for the $s p^{3}$-hybridized boraneyl groups at $\delta_{\mathrm{B}}=-4 \mathrm{ppm}$; this signal sharpens considerably at $193 \mathrm{~K}$ (Scheme $3 \mathrm{C}$ ). These data demonstrate the proclivity of the pendant boranes of the $\left[\mathrm{Ni}^{0}\left(\mathrm{P}_{2} \mathrm{~B}^{\mathrm{Cy}}{ }_{4}\right)_{2}\right]$ framework to support a metal-rich secondary coordination sphere, an attractive approach towards accessing multimetallic complexes that are "docked" via Lewis $\mathrm{acid} / \mathrm{base}$ interactions.

Previously, we showed that reaction of $\left[\mathrm{Ni}^{0}\left(\mathrm{P}_{2} \mathrm{~B}^{\mathrm{Cy}}{ }_{4}\right)_{2}(\mathrm{DMAP})_{8}\right]$ with $\mathrm{Phl}$ resulted in the formation of $\left[\mathrm{Ni}^{\prime \prime}\left(\mathrm{P}_{2} \mathrm{~B}^{\mathrm{Cy}}{ }_{4}\right)_{2}(\mathrm{DMAP})_{8}(\mathrm{I})\right]$ I via iodine atom abstraction. ${ }^{8}$ We thus wished to probe the reactivity of
6 with 4-fluoroiodobenzene; however, productive reactivity was not witnessed due to protection of the $\mathrm{Ni}(0)$ site by a "golden"

A. Synthesis of a 4-pyridylgold(I) reagent, $\mathbf{5}$.
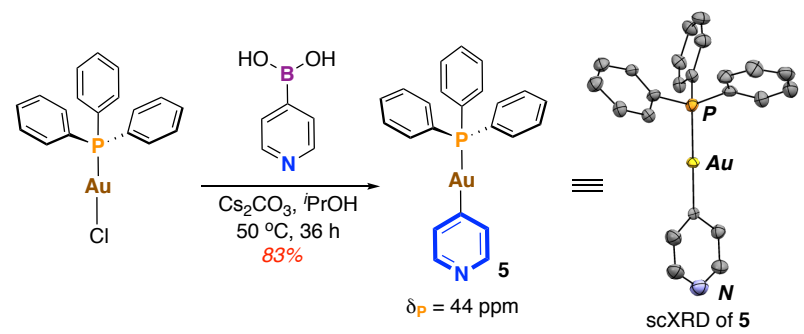

B. Generation of a "golden" secondary coordination sphere

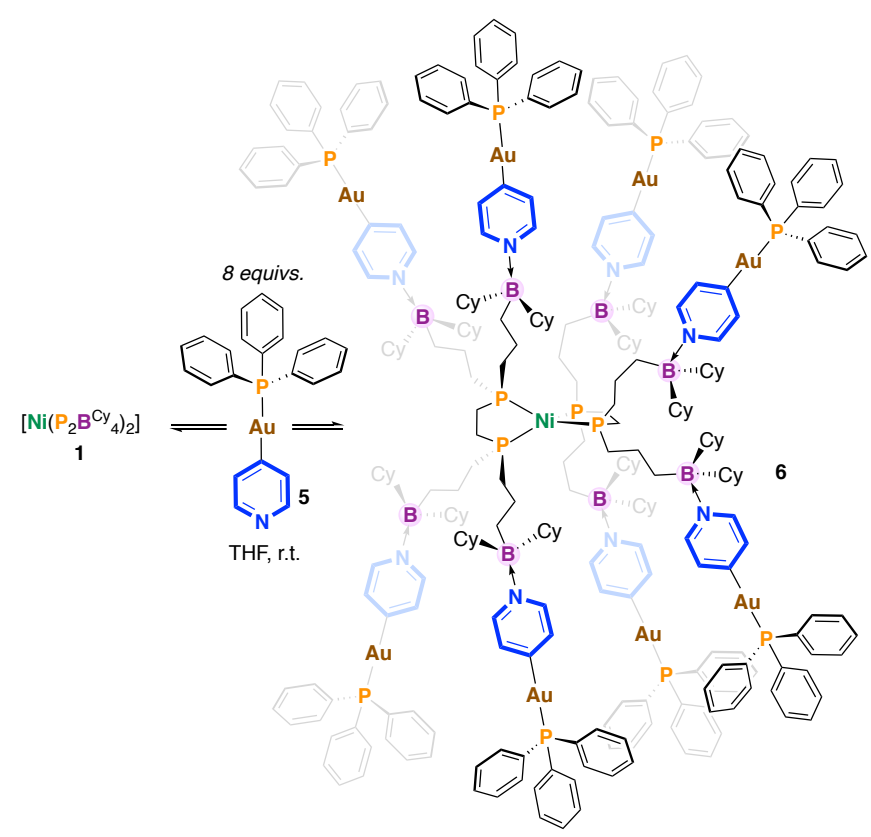

C. Variable temperature ${ }^{11} \mathrm{~B}$ NMR for $6,161 \mathrm{MHz}, \mathrm{THF}-\mathrm{d}_{8}$

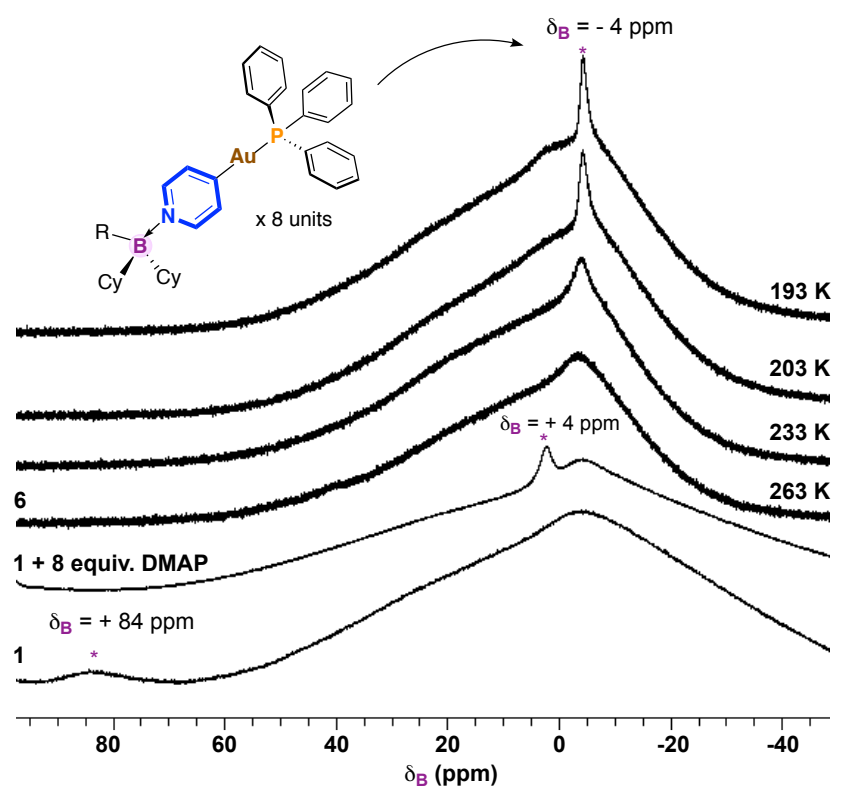

Scheme 3. A. Synthesis of a 4-pyridylgold(I) reagent 5. Inset shows the scXRD structure of $\mathbf{5}$ ( $50 \%$ occupancy, hydrogens omitted for clarity). B. Synthesis of octaaurated compound 6. C. ${ }^{11}$ B NMR spectroscopy (THF- $d_{8}$, $161 \mathrm{MHz}$ ). 
secondary coordination sphere, preventing oxidative addition. Nonetheless, switching the order of addition and first allowing 1 to fully react with 4-fluoroiodobenzene to give $\left[\mathrm{Ni}^{\prime \prime}\left(\mathrm{P}_{2} \mathrm{~B}^{\mathrm{Cy}}{ }_{4}\right)\left(4-\mathrm{FC}_{6} \mathrm{H}_{4}\right)(\mathrm{I})\right]$ $(\mathbf{2}-\mathrm{F})$, followed by addition of $\mathbf{5}$, provided the pyridyl-linked oligomer, $\left[\mathrm{Ni}^{\mathrm{II}}\left(\mathrm{P}_{2} \mathrm{~B}^{\mathrm{Cy}}{ }_{4}\right)\left(4-\mathrm{NC}_{5} \mathrm{H}_{4}\right)(\mathrm{I})\right]_{n}^{8}$ in $24 \%$ yield after 7 mins by ${ }^{31} \mathrm{P}$ NMR spectroscopy, which results from aryl-to-pyridyl transmetalation (Scheme 4). Under these reaction conditions 2-Pyr was noted to be more robust c.f. $\mathbf{2 - X}$, producing less of 3 ; 4-(4fluorophenyl)pyridine was not detected by ${ }^{19} \mathrm{~F}$ NMR spectroscopy. Interestingly, reaction between $\left[\mathrm{Ni}{ }^{\prime \prime}(\mathrm{d} n p p e)\left(4-\mathrm{FC}_{6} \mathrm{H}_{4}\right)(\mathrm{I})\right](3-\mathrm{F})$ and $\mathbf{5}$ in THF provides a cloudy reaction mixture and $\left[\mathrm{Ni}^{\prime \prime}(\mathrm{d} n \mathrm{ppe})(4-\mathrm{Pyr})(\mathrm{I})\right]$ is not observed.

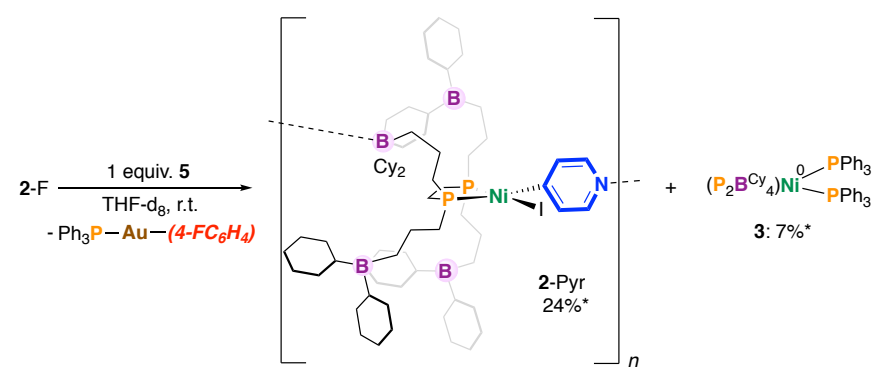

Scheme 4. Transmetalation using a Au-based 4-pyridyl reagent. * = Yield after $60 \mathrm{~min}$ (the maximum theoretical yield of $\mathbf{3}$ is $50 \%$ ).

In sum, we have confirmed that isolated $\left[\mathrm{Ni}^{\prime \prime}\right.$ (diphosphine)(Ar)(X)] compounds undergo aryl-for-aryl in addition to aryl-for-iodide transmetalation in the presence of arylgold(I) reagents. Furthermore, we have exploited the boron-rich secondary coordination sphere of $\left[\mathrm{Ni}\left(\mathrm{P}_{2} \mathrm{~B}^{\mathrm{Cy}}{ }_{4}\right)_{2}\right]$ to host a metal (gold)-rich secondary coordination sphere via pyridine-borane dative interactions, a starting point toward achieving metal-metal cooperativity using such boron-rich ligand scaffolds in an elementary cross-coupling transformation. This study expands our knowledge of Au-to-metal transmetalation and provides insights into the initial steps associated with metal-to-metal functional group transfer relevant to carbon-carbon cross-coupling.

The authors are grateful to the University of Windsor, the Council of Ontario Universities, Compute Canada, and the Natural Sciences and Engineering Research Council of Canada (Discovery Grant, RGPIN-2020-04480, Discovery Launch Supplement, DGECR2020-00183, and a graduate award (CGS-M) to J. A. Z.) for funding. This work was also made possible by the facilities of the Shared Hierarchical Academic Research Computing Network (SHARCNET: www.sharcnet.ca) and Compute/Calcul Canada. D. J. N. also thanks the Carnegie Trust for the Universities of Scotland for a Research Incentive Grant (RIG008165). Some of the calculations in this manuscript were performed using the Archie-WEST High Performance Computer at the University of Strathclyde; we thank Mr. J. Buzzard, Dr. K. Kubiak-Ossowska, and Dr. R. Martin for their assistance with this facility.

\section{Conflicts of interest}

There are no conflicts to declare.

\section{Notes and references}

${ }^{1}$ J. F. Hartwig, Organotransition Metal Chemistry From Bonding to Catalysis. Chapter 7, University Science Books, Mill Valley, California. 2010.

2 a) R. Jana, T. P. Pathak and M. S. Sigman, Chem. Rev. 2011, 111, 1417; b) N. Hazari, P. R. Melvin and M. M. Beromi, Nat. Rev. Chem. 2017, 1, 0025; c) K.
C. Nicolaou, P. G. Bulger and D. Sarlah, Angew. Chem. Int. Ed. 2005, 44, 4442.

${ }^{3}$ a) A. S. K. Hashmi, C. Lothschütz, R. Döpp, M. Rudoplh, T. D. Ramamurthi and F. Rominger, Angew. Chem. Int. Ed. 2009, 48, 8243; b) M. Hansmann, M. Pernpointner, R. Dopp and A. S. K. Hashmi, Chem. -Eur. J. 2013, 19, 15290.

4 J. J. Hirner and S. A. Blum, Organometallics 2011, 30, 1299.

${ }^{5}$ A. S. K. Hashmi and L. Molinari, Organometallics 2011, 30, 3457.

${ }^{6}$ Y. Shi and S. A. Blum, Organometallics 2011, 30, 1776.

${ }^{7}$ a) J. J. Hirner, Y. Shi and S. A. Blum, Acc. Chem. Res. 2011, 44, 603; b) L. -P. Piu and G. B. Hammond, Chem. Soc. Rev. 2012, 41, 3129.

8 J. A. Zurakowski, B. J. H. Austen, M. C. Dufour, D. M. Spasyuk, D. J. Nelson and M. W. Drover, Chem. -Eur. J. 2021, DOI: 10.1002/chem.202103121

9 a) C. Amatore, G. Broeker, A. Jutand and F. Khalil, J. Am. Chem. Soc. 1997, 119, 5176; b) P. Fitton and E. A. Rick, J. Organomet. Chem. 1971, 28, 287; c) A. L. Clevenger, R. M. Stolley, N. D. Staudaher, N. Al, A. L. Rheingold, R. T. Vanderlinden and J. Louie, Organometallics 2018, 37, 3259; d) G. Yin, I. Kalvet, U. Englert and F. Schoenebeck, J. Am. Chem. Soc. 2015, 137, 4164.

${ }^{10}$ C. Croix, A. Longeau-Balland, H. Allouchi, M. Giorgi, A. Duchêne and J. Thibonnet, J. Organomet. Chem. 2005, 690, 4835.

11 DFT calculations were carried out using Gaussian16 Rev. C.01 (Gaussian 16, Revision C.01, M. J. Frisch, et al., Gaussian, Inc., Wallingford CT, 2016) at the M06/6-311+G(d,p) + LANL2DZ $(d, p)+$ LANL2DZ(f) + SMD(benzene)//B3LYP-D3/6-31G(d) + LANL2DZ(d,p) + LANL2TZ(f) level of theory. DLPNO-CCD(T) single points were obtained using ORCA 5.0.0 on DFToptimised geometries using a cc-pVTZ-PP basis set and SK-MCDHF-RSC ECP on Au and I, and a cc-pVTZ basis set on all other atoms. For more details, see the Supporting Information.

12 a) C. Riplinger, P. Pinski, U. Becker, E. F. Valeev and F. Neese, J. Chem. Phys. 2016, 144, 024109; b) Riplinger, C.; Sandhoefer, B.; Hansen, A.; Neese, F. J. Chem. Phys. 2013, 139, 134101.

${ }^{13}$ M. W. Drover, M. C. Dufour, L. A. Lesperance-Nantau, R. P. Noriega, K. Levin and R. W. Schurko, Chem. -Eur. J. 2020, 26, 11180.

${ }^{14}$ For examples of Au-arene synthesis, see: a) N. Ahlsten, G. J. P. Perry, X. C. Cambeiro, T. C. Boorman and I. Larrosa, Catal. Sci. Tech. 2013, 3, 2892; b) N. V. Tzouras, M. Saab, W. Janssens, T. Cauwenbergh, K. Van Hecke, F. Nahra and S. P. Nolan, S. P. Chem. -Eur. J. 2020, 26, 5541; c) F. J. L. Ingner, Z. X. Giustra, S. Novosedlik, A. Orthaber, P. J. Gates, C. Dyrager and L. T. Pilarski, L. T., Green Chem. 2020, 22, 5648; d) D. V. Partyka, M. Zeller, A. D. Hunter and T. G. Gray, Inorg. Chem. 2012, 51, 8394.

${ }^{15}$ This reaction mixture precipitated from benzene or toluene, and required THF as solvent. Notably, both components ( $\mathbf{1}$ and $\mathbf{5}$ ) are soluble in benzene or toluene, indicating persistent adduct formation. 